\title{
BMJ Open Feasibility of health systems strengthening in South Sudan: a qualitative study of international practitioner perspectives
}

\author{
Abigail Jones, ${ }^{1}$ Natasha Howard, ${ }^{1}$ Helena Legido-Quigley ${ }^{1,2}$
}

To cite: Jones A, Howard N, Legido-Quigley $\mathrm{H}$. Feasibility of health systems strengthening in South Sudan: a qualitative study of international practitioner perspectives. BMJ Open 2015;5:e009296.

doi:10.1136/bmjopen-2015009296

- Prepublication history for this paper is available online. To view these files please visit the journal online (http://dx.doi.org/10.1136/ bmjopen-2015-009296)

Received 2 July 2015 Revised 19 September 2015 Accepted 9 November 2015

\section{a CrossMark}

${ }^{1}$ Faculty of Public Health and Policy, London School of Hygiene and Tropical Medicine, London, UK ${ }^{2}$ Saw Swee Hock School of Public Health, National University of Singapore

Correspondence to Dr Helena Legido-Quigley; Helena.Legido-Quigley@ Ishtm.ac.uk

\section{ABSTRACT}

Objective: To explore the feasibility of health systems strengthening from the perspective of international healthcare implementers and donors in South Sudan.

Design: A qualitative interview study, with thematic analysis using the WHO health system building blocks framework.

Setting: South Sudan.

Participants: 17 health system practitioners, working for international agencies in South Sudan, were purposively sampled for their knowledge and experiences of health systems strengthening, services delivery, health policy and politics in South Sudan.

Results: Participants universally reported the health workforce as insufficient and of low capacity and service delivery as poor, while access to medicines was restricted by governmental lack of commitment in undertaking procurement and supply. However, progress was clear in improved county health department governance, health management information system functionality, increased health worker salary harmonisation and strengthened financial management

Conclusions: Resurgent conflict and political tensions have negatively impacted all health system components and maintaining or continuing health system strengthening has become extremely challenging. A coordinated approach to balancing humanitarian need particularly in conflict-affected areas, with longer term development is required so as not to lose improvements gained.

\section{INTRODUCTION}

Following decades of conflict, and independence from Sudan on 9 July 2011, civil conflict resumed in South Sudan on 15 December 2013. ${ }^{12}$ Accusations by President Salva Kiir of a coup attempt by dismissed deputy Riek Machar, led to fighting between dominant Nuer and Dinka ethnic groups. Recently, sanctions were imposed by the UN Security Council on six generals from both sides, including Kiir and Machar, who were

\section{Strengths and limitations of this study}

- This is the first study to explore reported perceptions of achievements, challenges and lessons learnt during the ongoing process of health system strengthening on South Sudan.

- Adds to a growing literature on experiences of health system strengthening in conflict-affected settings.

- The limited number of participants and complex context (eg, acute conflict, funding and travel restrictions) limit generalisability and demonstrate need for further research.

accused of fuelling conflict in South Sudan. ${ }^{3}$ Violent conflict has focused on states where oilfields are located, namely Jonglei, Unity and Upper Nile, with both sides employing internationally unacceptable tactics including sexual violence. ${ }^{4}$ Peace negotiations began in January 2014, and have been criticised for broken cease fires and failure to form an interim government.

South Sudan faces a humanitarian crisis, with more than 10000 people killed, approximately 1.4 million internally displaced, and 0.5 million refugees fleeing. ${ }^{6}$ South Sudan already had some of the worst health indicators globally. Maternal mortality was estimated at 2054/100 000 live births, under-5 mortality at 105/1000 live births, ${ }^{7}$ and girls more likely to die in pregnancy or childbirth than complete primary school. ${ }^{8}$

Chronic conflict has left the health system underdeveloped with non-governmental and faith-based organisations (NGOs and FBOs) providing approximately $70 \%$ of services. ${ }^{9}$ Governmental health sector contribution are a low $4 \%$ of national budget. ${ }^{9}$ Since 2012 , a donor funding mechanism (ie, the US Agency for International Development (USAID), World Bank (WB) and Health Pooled Fund (HPF) led by the UK Department for International Development) 


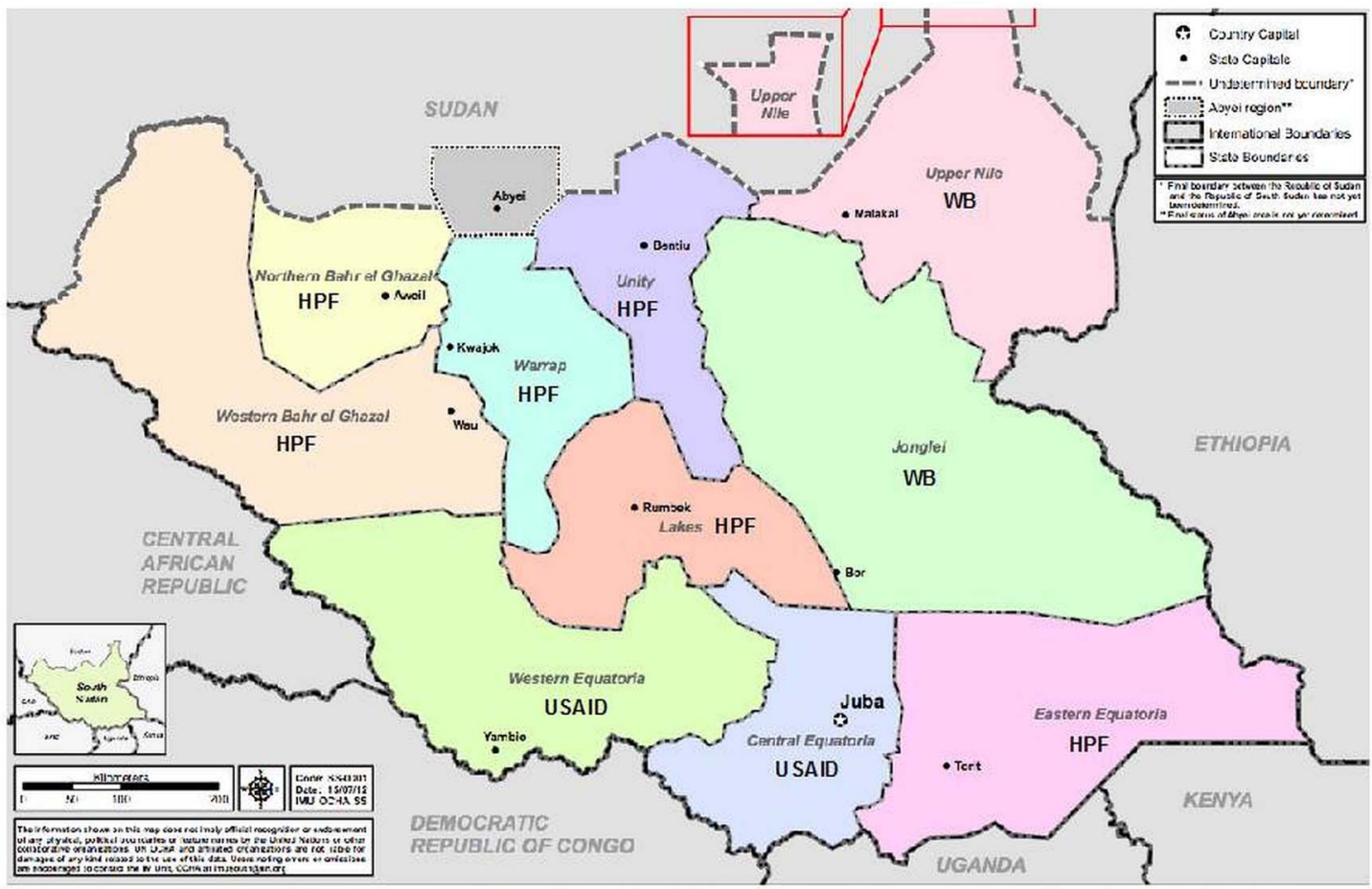

WB - World Bank, USAID - United States Agency for International Development, HPF - Health Pooled Fund [consisting of Australian Agency for International Development (AusAid), the Canadian International Development Agency (CIDA), the Department for International Development (DFID), the European Commission (EC) and the Swedish International Development and Cooperation Agency (SIDA)]

Figure 1 Map of South Sudan showing distribution of donor funding mechanisms (United Nations Office for the Coordination of Humanitarian Affairs, 2012).

has financed primary healthcare services across the 10 South Sudanese states (figure 1). ${ }^{10}$ Like Afghanistan, South Sudan implements a Basic Package of Health Services (BPHS) for all citizens, often contracted to nonstate providers. ${ }^{11}$

South Sudan is classified as fragile by widely accepted assessment frameworks (ie, WB Country Policy and Institutional Assessment, Fund for Peace Failed States Index, Uppsala Conflict Database).${ }^{12}{ }^{13}$ While no universally agreed definition of fragility exists, it is characterised by lack of government legitimacy through failure to meet citizens' basic needs and expectations (eg, security, rule of law, basic services). ${ }^{14}$ Fragile and conflict-affected countries, including South Sudan, are furthest from achieving global development targets (eg, Millennium Development Goals) and estimations indicate over half the world's poor will live in fragile situations by $2018 .{ }^{12}$

International agencies have historically focused on disease-specific interventions in South Sudan. However, health systems strengthening (HSS) is increasingly seen as more effectively improving health outcomes for the poorest. ${ }^{15}$ There is relatively little published research on HSS in fragile situations ${ }^{14}{ }^{16-22}$ and this study contributes to filling a research gap. With recurrence of conflict and classification by the WHO Director General as a grade 3 emergency, ${ }^{23}$ this study comes at a critical time.

This study aims to explore the feasibility of HSS in South Sudan, through perspectives of a range of international health system practitioners, by describing
HSS-related achievements and challenges international agencies have encountered, analysing agencies' adaptations to working in a fragile context, and concluding with recommendations for South Sudan and potentially other conflict-affected countries.

\section{METHODS}

\section{Study design and sampling}

A qualitative study design was chosen to explore the values and perceptions of health system practitioners, given the limited published literature available on South Sudan. Semi-structured interviews, chosen for their flexibility, richness of detail and ability to provide common material for analysis, were used to gather detailed primary data organised using the WHO health system framework. ${ }^{24}$ This describes six health system building blocks (ie, service delivery, health workforce, health information, essential medicines, health financing, leadership and governance) and is arguably the most widely recognised health system framework.

Though WHO's framework is criticised for being descriptive and lacking interaction between building blocks or with demand-side factors, ${ }^{25}{ }^{26}$ it provides a common language valuable in health systems thinking ${ }^{25}$ and has been used for studies in Afghanistan, ${ }^{11}$ Myanmar $^{27}$ and Zambia. $^{28}$ WHO defines HSS as "improving these six health system building blocks and managing their interactions in ways that achieve more 
equitable and sustained improvements across health services and health outcomes". ${ }^{24}$

Participants were initially identified by snowball sampling and recruited purposively, for diversity of professional experience across South Sudan (eg, senior managers, independent consultants, front-line implementers). A sample of 20 participants was sought to gain appropriate detail in the available timeframe.

\section{Data collection and analysis}

A semistructured topic guide was developed using the WHO framework with additional open-ended questions to prompt discussion and incorporate new topics identified in interviews or related to participant areas of work. Interviews were conducted by AJ in July to August 2014, face-to-face in UK locations selected by participants or via Skype or telephone. Each, lasting approximately $1 \mathrm{~h}$, was conducted in English, digitally recorded and transcribed.

Transcripts were managed and coded by AJ using NVivo V.10 software. Thematic analysis was performed ${ }^{29}$ initially using the WHO framework with additional themes, categories and subcategories developed inductively and relevant phrases coded. Emergent themes were reviewed by HL-Q and thematic analysis of initial interviews was used to inform and refine topics for discussion in subsequent interviews. Authors adopted techniques from the constant comparative method, including line-by-line analysis of early interviews, use of subsequent interviews to test preliminary assumptions, comparison of codes and cases across the data set, and identification of deviant cases. ${ }^{30} 31$ Reporting adheres to COREQ criteria for qualitative research. ${ }^{32}$

\section{Ethics}

All participants received study information sheets and written informed consent was recorded. Interviews were conducted confidentially, with data anonymised by assigning participants numbers and removing identifying information from transcripts (eg, organisation name, title, location), and stored securely in locked files.

\section{RESULTS}

The study included 17 participants from seven international NGOs, two international FBOs and four major donors (table 1). Of 30 people invited, 7 did not respond and 6 could not schedule interviews within the study period. Twelve women and five men participated, of five different nationalities, including two South Sudanese citizens living in the UK. Findings are presented under WHO framework and two emergent themes; one that cut across all building blocks (ie, political tensions) and one linking all building blocks (ie, HSS). Subheadings illustrate salient points within each theme.

\section{Services delivery}

Health services quality

This was reported as poor by all participants, with one commenting quality was "probably the worst in the
Table 1 Participants' summary

\begin{tabular}{ll}
\hline Agency and role & Number \\
\hline Donor/funding mechanism technical advisor & 2 \\
MOH technical advisor & 3 \\
Donor/funding mechanism freelance consultant & 2 \\
INGO senior manager & 7 \\
INGO supervisor/front-line provider & 1 \\
IFBO supervisor/front-line provider & 2 \\
\hline IFBO, international faith-based organisation; INGO, international \\
non-governmental organisation; MOH,Ministry of Health.
\end{tabular}

world" (P12). Disparities were reported between providers. Health services provided through the humanitarian response were identified as comparatively good with "24-hour service provision" (P7), wider service variety and fully trained health workers. Services managed solely by the Ministry of Health $(\mathrm{MOH})$ were reported as lower quality.

They (MOH facilities) didn't have things like drugs, they were poorly staffed, they wouldn't pay salaries...you would just find a building, no staff and no patients. (P8)

\section{Access barriers}

Several barriers were mentioned, including long walking distances, poor weather in the rainy season, healthcare staff not returning to facilities after lunch, and a lack of educated women and therefore female healthcare workers.

The lack of educated women, as well as very few women who could actually get in to the health workforce...is, in terms of antenatal care, [...] quite a barrier to get the uptake to access those kinds of services. (P11)

All facilities were "committed to implementing the MOH Basic Package of Health Services" (P15). The BPHS, which detailed which interventions should be available for primary healthcare, was identified by most as very ambitious. However, most indicated it was important "to have something to work towards" (P8) and "keep within the South Sudanese system as much as possible" (P7).

\section{Impact of conflict}

All described the negative impact of political conflict on health services. Community-based programmes in Unity State were discontinued due to "active landmine laying" (P11). Primary healthcare facilities were looted and destroyed by both government and opposition forces. "You just see both sides pretty devastatingly attacking healthcare centres and burning things down and looting and stealing" (P14). One participant described the destruction of a clinic in Upper Nile State.

The [name] Army went through [name] clinic and killed inpatients in there [...] including an eight-year-old boy [...]. The pharmacy was trashed and there was a skull on the floor. (P8) 
Functioning facilities were reported as overwhelmed by population movements.

There's a lot of returnees, lots of people from Khartoum just ended up in [name], and they're really struggling. It's a primary healthcare centre but it's functioning as a hospital. (P16)

A few participants described contingency plans for population fluctuations.

It's a case of working out where the displaced population are and going to, then [...] setting up mobile health facilities and mobile teams that go and visit once a week or however often they need to go. (P2)

Participants did not discuss how health planning might mitigate ongoing volatility in South Sudan, focusing instead on contingency responses and long-term health system strengthening goals. A few stated concerns about donor funds rebuilding health facilities that may be destroyed again if conflict continued.

Why put money into health systems strengthening and put money into building a system which might be destroyed by a civil war? (P14)

\section{Workforce}

\section{Capacity and shortages of health workers}

All participants reported insufficient numbers and capabilities of health workers as the biggest health sector challenge in South Sudan. Most participants mentioned health workforce as crucial to HSS with health worker capacity a major issue "particularly in areas that have been subjected to a prolonged conflict" (P8). Decades of civil war "resulted in very low levels of education [and] very few training opportunities" (P16).

Rural areas suffered most, with fewer educational opportunities and urban preferences of trained professionals.

\begin{abstract}
As soon as people have any kind of higher level qualification you might not necessarily get them back to the areas which most need them. The areas that are the most understaffed and have the lowest capacity, the lowest literacy rates and the lowest education opportunities are the areas that are very isolated, and that is a problem. Because when they go back they don't want to stay, they want to go and work in the city $[\ldots]$ where they can make more money and have a better quality of life. (P4)
\end{abstract}

Health worker shortages were reportedly exacerbated by the absence of a pension system, as health workers remained on the $\mathrm{MOH}$ payroll until death.

Most people are not getting pensioned off, they basically keep working until they die [...] It would be better to pension them off, then that would create vacancies which would be filled. (P15)

\section{Training}

Primary health worker numbers were insufficient to meet BPHS standards, with severe shortages of mid-level cadres (eg, nurses, midwives, clinical officers). Health services relied heavily on community health workers (CHWs). However, MOH stopped CHW training in 2012 to elevate facility staff cadres, a decision universally criticised.

That cadre of health worker takes two, three or four years to train and in the meantime you are chronically low on staff. (P8)

Clinical placements for students were described as poor and not offering "good learning and working experiences" (P6). Nurse mentors were reported as unqualified or unavailable.

When they would turn up, all the nurses that were supposed to be mentoring them would go home [...]. The nurse students were supposed to be mentored by these nurses who actually most of them weren't nurses... (P16)

\section{Health information}

\section{District Health Information System}

In 2011, a District Health Information System II (DHIS) software package was introduced in South Sudan. Most participants considered this government-led initiative, as a relative success.

I think one of the good things about DHIS, is a kind of a success story to some degree, and in South Sudan it's pretty amazing considering the context. (P17)

The DHIS was described as a common reporting format for health indicators, meaning "it has been possible to harmonise government and NGO systems" (P12). Though one participant commented that "information is [...] not used for improved evidence based policy making or improving the management functions" (P6), several described positive examples of organisations working closely with county health departments (CHDs) to look at data trends and plan services accordingly.

What they [NGO and CHD] were doing was looking at the data and if [organisation] were coming in and saying we want to do a malaria campaign in this area, then the counties were saying actually no [...], don't go to this payam [administrative area], go to this payam [...]. So they were using it for coordinating the work of NGOs as well as coordinating their own work. (P16)

\section{Essential medicines}

\section{Procurement and supply chain management}

All participants noted that procurement and supply chain management was extremely challenging in South Sudan. $\mathrm{MOH}$ was responsible for pharmaceutical supply to all primary healthcare facilities, including those managed by NGOs, but operated a push system (ie, dependent on forecasting rather than demand) unresponsive to needs. Many 
participants said they received wrong amounts or supplies. "You could get anti-leishmaniasis [medication] coming to Western Equatoria where there is no leishmaniasis" (P4). Stock-outs and expired drugs were commonly mentioned.

\section{Emergency Medicines Fund}

Austerity measures, caused by oil pipeline disagreements with Sudan, prevented $\mathrm{MOH}$ taking over medicines supply in 2012. USAID, the UK Department for International Development (DFID) and Norad established a 1-year Emergency Medicines Fund (EMF) to address gaps. Despite procurement beginning in 2012, first consignments only arrived in country in June 2014 and "2013 was characterised by huge stock-outs all across the country" (P5). Additionally, EMF drugs were not supplied to the three conflict-affected states.

There is no drugs that are being sent right now to Unity and Jonglei and Upper Nile, because they say it's too unstable. But it's basically because the government doesn't want to send any drugs to rebel controlled areas. (P5)

Participants noted no plans had been announced to replace the 1-year EMF supply, despite it being raised at several high-level meetings, indicating further stock-outs were likely.

\section{Health financing}

\section{Government funding and harmonisation}

Although most participants agreed the government could contribute more health sector funding, one reported "a lot of progress... [and some] very real health systems strengthening going on" (P15) in public financial management and funds transfer from national to subnational levels.

Several reported the "Ministry of Health took the lead" (P17) on first reducing then harmonising salaries between BPHS implementers, so payments within a defined salary scale had improved staff retention. In January 2015, government health worker salaries were to increase " $80 \%$ on average" (P15) to align with the harmonised salaries scale. Several expressed concern over "the more emergency-focused NGOs who aren't...using a harmonised salary scale" (P12), which risked undermining the hard-won government system.

\section{Donor funding}

The USAID/WB/HPF funding mechanism, introduced in 2012, was considered "the only way to finance health services" (P8) and "more sustainable" (P8) than previous short-term ad hoc humanitarian approaches. The single lead NGO per county model, implemented through the donor funding mechanism, was also described positively as it "really started to up the support to the county structures" (P8). Criticisms of the mechanism included too little funding and insufficient absorptive capacity: "There are no systems in place to absorb the funds, to use it wisely, to plan for it, to monitor for it" (P6). Several complained about inadequate flexibility to respond to emergencies.

Most reported that "the Ministry of Health definitely has a say with the donors about where they would like the money to go" (P14). However, bilateral funders reportedly pursued home country agendas, sometimes above health priorities. For example:

[name] has a really big thing right now with maternal health so a lot of what they fund goes to maternal health, and that's just because that's an easy sell for them and their parliament. (P14)

\section{Leadership and governance}

"Good leadership and good governance" (P6) and "transparency and accountability" (P6) were listed as essential to HSS and building trust with partners. "Partner engagement with the government over implementation" (P15) was reported as important for government ownership and involvement.

\section{Ministry of Health}

South Sudan's health system was described as decentralised, with $\mathrm{MOH}$ responsible for developing policies and guidelines and allocating the budget and state ministries and CHDs overseeing implementation. A few participants said $\mathrm{MOH}$ led on overseeing and guiding the health system, while the majority suggested the health system seemed supported by international agencies.

The system is supported almost wholly by international NGOs, by external funding, by faith-based organisations and then there is a not particularly high capacity Ministry of Health trying to hold it all together. (P8)

Some expressed concern that external dominance had worsened since conflict returned in December 2013.

The whole reason behind the [name] health programme was to support the transition from NGO-led to government-led health services and within a night that had completely gone. Once again the international community had come in and was managing the health system in South Sudan. (P16)

\section{County health departments}

At county level, while a few noted poor capacity and infrastructure, one mentioned that " 30 out of 39 counties just had a county plan written...so that's a massive step forward" (P12), and many remarked positively on CHD capacity.

When I went around meeting a lot of the County Health Departments, they knew their patches in terms of who was where and what they were doing and they read all the request for proposal documents and had views, and they had more capacity than I had been led to believe of them. (P17) 
Several noted improvements in CHDs capacity over time.

I would have met the county 10 years ago, and it was one guy who didn't understand what his role was. Now there's a team of four, they understand their roles, they understand what [NGO's] role is and they have a much higher level of understanding of how we can work together. (P13)

\section{Political tensions}

After independence, participants had been optimistic South Sudan could transition from poverty to peace and stability. They had anticipated issues with cattle raiding or further conflict with Sudan, but a political crisis within South Sudan was not foreseen. However, austerity measures from 2012 contributed to a "downward slide until December 2013 when the whole place collapsed into another civil war" (P8).

Several mentioned open discrimination in the health system. Many MOH staff fled during December 2013 and a number of Nuer staff, including the Director General for Medical Training and Professional Development, were forced to relocate to camps. A participant noted that "Kiir and his people, the Dinka people, have become increasingly tribalistic in their management" (P6).

Ethnicity was reported as a barrier to healthcare access in some areas. Certain tribes have not been granted access to work in particular areas. For example, Nuer people were reportedly afraid to access a major teaching hospital run primarily by Dinka staff. "We can't bring them here because we don't trust the doctors or the security guards in [name] Hospital and the people won't come themselves" (P14). One participant listed the ethnicities permitted to work in a county in Upper Nile State. "Only white people, Ethiopians and Nuers were welcome...if you were Kenyan, Ugandan, Equatorian or Dinka you would not be permitted to be working or living there" (P8).

A number of participants expressed concern over "the ethics around supporting a government at war" (P16). While a few participants said the government wanted to provide basic services throughout the country and was attempting to do so, many stated government spending priorities were not aligned with this.

The government has just bought a bunch of arms for a million dollars but...they're always looking at the donors to fill the health gaps. So really you can buy guns so everybody can shoot at each other but you can't manage to invest in the health system, and that's the reality of the situation. It's so sad. (P9)

\section{Health systems strengthening}

Participants were optimistic about HSS feasibility in South Sudan. Though identifying it as a slow process of "baby steps" (P12), most said it should be prioritised in both development and emergency responses.
I think it's going to be a slow process that's probably going to take decades [...] but that's not a reason not to do it and I think actually it should be the way that we frame all of our work as international actors in South Sudan, both in the emergency response and longer term development. (P11)

Many mentioned that, despite the difficulties in South Sudan, they had seen HSS progress over the years.

I think a lot of progress has been made. I mean quite a dramatic amount of progress actually has been made [...] despite the problems [...] So, I slowly think that we are seeing very real health systems strengthening going on that will quite quickly have a significant impact on people's lives. (P15)

A small number were less optimistic about HSS prospects, with one commenting that since conflict broke out in 2013, focus should be on humanitarian rather than longer term development needs. "I think pre-December, yes I was quite optimistic [...] now I think really the focus has to be on emergency response" (P7). Participants acknowledged that in conflict-affected areas, life-saving humanitarian support was most critical. However, several noted "as you do emergency services, begin to think about the long-term" (P4) and this had not happened in South Sudan where "the health system has been thought of a bit late" (P4). A few mentioned that renewed conflict made it harder to persuade donors to fund longer term health programmes in South Sudan, particularly as health facilities had been deliberately targeted.

There's been a lot of targeted killings at health centres and I think that makes people less inclined to want to continue to support the health system and it makes humanitarian aid a much easier sell than development aid. (P14)

Thus, most agreed HSS might not be possible in the three conflict-affected states, but should be an achievable priority in stable areas to prevent losing everything accomplished so far.

There's many parts of the country where people do operate as normal and in those areas we need to have a functioning drug system [...] a payroll system in place [...] we've worked really hard to get a monitoring information system up [...] If we don't continue to put efforts in $[\ldots]$ we lose all of this that we've been working on for the last 10 years. (P14)

\section{DISCUSSION}

Health service quality was universally perceived as poor and often difficult to access with those managed by $\mathrm{MOH}$ being of the lowest quality. The situation has worsened since resurgent conflict, with health facilities destroyed, closed or overwhelmed, and reduced health infrastructure funding availability, as similarly reported in Iraq. ${ }^{33}$ 
The limited capacity and insufficient numbers of healthcare workers was identified as the greatest health sector challenge, supporting findings from Roome $e t a l^{35}$ and others. ${ }^{11} 34$ The contribution to health worker shortages of $\mathrm{MOH}$ plans to rely on mid-level cadres was found in postconflict Liberia, and South Sudan may reinstate CHW training, based on the Ethiopian model of health extension workers. ${ }^{16} 36$

Kevany et al recommend strategies for the effective implementation of monitoring and evaluation activities in South Sudan, specifically emphasising the importance of harmonisation activities among partners. ${ }^{37}$ This has been achieved to some extent with the relative success of the DHIS.

Stock-outs of essential medicines were reported as a common occurrence. Participants commented that this was likely to continue unless the government accepted responsibility for procurement and supply chain management as previously agreed. However, deliberate obstruction of the supply chain to conflict-affected areas by government forces highlights the complications of working through government systems when government has vested interest in the conflict.

Progress was described in health financing, particularly in relation to harmonisation of health worker salaries. Leadership and governance was reported as improved at the county level, aligning with Newbrander et $a l \mathrm{~s}^{18}$ recommendation to develop decentralised managerial capacity in postconflict settings. However, South Sudan is not yet postconflict and cannot conveniently be treated as such. Reported importance of effective leadership and governance supports the literature on coordination and accountability. ${ }^{38-41}$ However, participants contested $\mathrm{MOH}$ prominence in HSS, noting the importance of international agencies since conflict resumed in 2013, and focused on MOH's external accountability (eg, to international partners) with little discussion of its accountability and legitimacy role to citizens and communities. ${ }^{42}{ }^{43}$ Trust was reported to have broken down between the government and international community as a result of political and ethnic tensions and open discrimination was described in the health sector.

HSS priorities in South Sudan, as common in conflict-affected countries, include building human resources capacity, providing acceptable basic services, and ensuring effective governance. The majority of participants believed that HSS was feasible and should be a priority in the more stable states. A small number of participants commented that the focus should be on humanitarian aid.

\section{Implications for research and practice}

Humanitarian, security, political and economic realities encourage international agencies to engage with fragile situations, ${ }^{14}{ }^{41}$ including mounting research indicating health services improvements can contribute to wider state-building efforts. ${ }^{21}{ }^{44-47}$ Kevany recommends specific criteria to achieve diplomatic and foreign policy goals and advocates that these be an explicit component of health programming. ${ }^{48}$

HSS is challenging in fragile and conflict-affected settings, with international engagement widely considered necessary for success. ${ }^{15} 41$ Funds and technical support from international partners play a key role in government legitimisation, resource mobilisation and capacity strengthening. ${ }^{40}$ However, international support is often criticised as inefficient or insufficiently effective ${ }^{49}$ and recent proliferation of global institutions and harmonisation initiatives can be difficult to translate into nationallevel HSS improvements. ${ }^{34}$ This is further complicated by the differing agendas and approaches of short-term humanitarian and long-term development actors and funding mechanisms, as noted by study participants given South Sudan's resurgent conflict.

While the HSS agenda is gaining momentum, disagreement remains in defining and operationalising it. ${ }^{27}$ Participants expressed similar views on: (1) building within-country capacity; (2) developing effective leadership and governance, including transparency and accountability, to increase trust between international partners and government; and (3) requiring both international partners and government to work within government structures whenever feasible, commit to longer term plans, and ensure government leadership on HSS. Crucially, government must lead on addressing root causes of the continued conflict to be seen as legitimate and accountable externally and internally, which is necessary for HSS success. ${ }^{2}$ Views on the feasibility of HSS in fragile and conflict-affected situations varied, though most participants considered HSS a priority for South Sudan. Longer term development support necessary for HSS has become harder to attract in South Sudan, as donors prioritise humanitarian aid that tends to parallel or subsume rather than strengthening existing systems. HSS in South Sudan requires careful balancing between the development support needed to build and strengthen the health system and parallel humanitarian efforts needed to ensure political violence is addressed and does not spread. The limited literature on HSS in chronic conflict-affected settings indicates a need for further research on more effective ways to coordinate humanitarian and development responses. ${ }^{49} 50$

This study highlighted that HSS requires engaging with non-health issues that can disrupt services provision and access in fragile and conflict-affected situations. These include political constraints and tensions that can affect anything from what resources are prioritised and for whom to which groups access basic services. Considerable ethical dilemmas arise from working with a government at war. ${ }^{51}$ Limitations of the WHO framework must also be acknowledged. While supporting those detailed elsewhere, ${ }^{25} 2728$ HSS during conflict requires additional focus on political realities (eg, security, funding constraints, workforce decimation) and interactions of building blocks within a complex and dangerous 
environment. $^{52}$ Further theoretical and empirical $^{2}$ research is particularly pressing in conflict-affected settings, where both extreme need and elevated risk can discourage research funding and implementation.

\section{Limitations}

Authors could not interview national staff or service users due to resource constraints and travel restrictions. Such perspectives would have provided greater diversity and balance. However, the sample included participants working in South Sudan and those who had left, allowing for differing perspectives. Those in South Sudan reported both greater optimism and concerns about discussing controversial topics, possibly reflecting vested interests, less perceived independence or simply professional 'burn-out' among those in country. As most participants were not front-line providers, their perspectives naturally reflected policy and administrative concerns. Interviews reflected personal experiences and perceptions that may not represent reality, while daily changes in South Sudan made capturing context at more than one point in time particularly difficult. Nonetheless, given the limited literature on South Sudan, this study offers a deeper understanding of HSS and builds on previous work conducted in chronic conflict and early stages of recovery. ${ }^{39}$

\section{CONCLUSION}

Health System Strengthening is extremely challenging in the fluctuating and risky context of South Sudan, with periods of active conflict and relative peace. The increased risk of violence means donors and international agencies are again inclined towards humanitarian over development investments in South Sudan. The deliberate targeting of health infrastructure has worsened the situation. Health system challenges remain, most notably in the health workforce and service delivery. Nevertheless, significant progress was reported. Some counties have developed competent health leadership, harmonisation of health worker salaries has improved staff retention, and software has improved health data management. Therefore, most participants concluded HSS is possible and should be prioritised in those states relatively unaffected by conflict, to prevent losing the significant gains made in this challenging environment.

\section{Acknowledgements Authors thank participants for their time and interest.}

Contributors AJ conceived the study, collected and analysed data, and drafted the manuscript. NH contributed to context and data interpretation, and critically revised the manuscript. HL-Q supervised study design and implementation and critically revised the manuscript. All authors approved the version for submission.

Funding This research received no specific grant from any funding agency in the public, commercial or not-for-profit sectors.

Competing interests None declared.

Ethics approval Ethics Committee London School of Hygiene and Tropical Medicine Research Ethics Committee.
Provenance and peer review Not commissioned; externally peer reviewed.

Data sharing statement No additional data are available.

Open Access This is an Open Access article distributed in accordance with the Creative Commons Attribution Non Commercial (CC BY-NC 4.0) license, which permits others to distribute, remix, adapt, build upon this work noncommercially, and license their derivative works on different terms, provided the original work is properly cited and the use is non-commercial. See: http:// creativecommons.org/licenses/by-nc/4.0/

\section{REFERENCES}

1. Pendle N. Interrupting the balance: reconsidering the complexities of conflict in South Sudan. Disasters 2014;38:227-48.

2. Hutton L. SOUTH SUDAN from fragility at independence to a crisis of sovereignty. The Hague: Conflict Research Unit, The Clingendael Institute, Netherlands Institute of International Relations, 2014.

3. BBC News. South Sudan Conflict: UN imposes sanctions on generals. 6 September 2015

4. Office of the Special Representative of the Secretary-General for Sexual Violence in Conflict, Sexual violence in conflict: South Sudan, from the Report of the Secretary-General to the Security Council (S/2015/203). 2015. http://www.un.org/ sexualviolenceinconflict/countries/south-sudan/

5. International Crisis Group. South Sudan: a civil war by any other name. 2014. http://www.crisisgroup.org/en/regions/africa/horn-ofafrica/south-sudan/217-south-sudan-a-civil-war-by-any-othername.aspx

6. UNOCHA. South Sudan Crisis: humanitarian snapshot (as of 29 September 2014). 2014. http://reliefweb.int/sites/reliefweb.int/files/ resources/South Sudan Humanitarian Snapshot 29Sept2014.pdf

7. $\mathrm{MOH}$. The Republic of South Sudan: the Sudan Household Health Survey 2010. National Bureau of Statisics, 2010.

8. UNICEF. Towards a baseline: best estimates of social indicators for Southern Sudan. New Sudan Centre for Statistics and Evaluation, 2004.

9. $\mathrm{MOH}$. Health sector development plan 2012-2016. Government of South Sudan, 2012

10. $\mathrm{MOH}$. International Health \& Coordination. 2015 (accessed 28 Jan 2015).

11. Howard N, Woodward A, Patel D, et al. Perspectives on reproductive healthcare delivered through a basic package of health services in Afghanistan: a qualitative study. BMC Health Serv Res 2014; 14:359.

12. OECD. Fragile states 2014: domestic revenue mobilisation in fragile states. OECD-DAC International Network on Conflict and Fragility (INCF), 2014

13. World Bank. Harmonised list of fragile situations FY15. 18.01.15. 2015.

14. Newbrander W, Waldman R, Shepherd-Banigan M. Rebuilding and strengthening health systems and providing basic health services in fragile states. Disasters 2011;35:639-60.

15. Hafner T. Shiffman J. The emergence of global attention to health systems strengthening. Health Policy Plan 2013;28:41-50.

16. Lee PT, Kruse GR, Chan BT, et al. An analysis of Liberia's 2007 national health policy: lessons for health systems strengthening and chronic disease care in poor, post-conflict countries. Global Health 2011;7:37.

17. Newbrander W. Providing health services in fragile states. Basic support for institutionalising child survival (BASICS) for the United States Agency for International Development (USAID); Arlington, VA, 2006.

18. Newbrander W, Peercy C, Shepherd-Banigan M, et al. A tool for assessing management capacity at the decentralized level in a fragile state. Int J Health Plann Manage 2012;27:276-94.

19. Alonso A. Brugha R. Rehabilitating the health system after conflict in East Timor: a shift from NGO to government leadership. Health Policy Plan 2006;21:206-16.

20. Petit D, Sondorp E, Mayhew S, et al. Implementing a Basic Package of Health Services in post-conflict Liberia: perceptions of key stakeholders. Soc Sci Med 2013;78:42-9.

21. Rubenstein LS. Post-conflict health reconstruction: search for a policy. Disasters 2011;35:680-700.

22. Percival V. Sondorp E. A case study of health sector reform in Kosovo. Confl Health 2010;4:7.

23. WHO. Humanitarian health action: South Sudan appeal documents. 2014 [cited 2014 19th June]. http://www.who.int/hac/crises/ssd/ appeals/en/ 
24. WHO. Everybody's business: strengthening health systems to improve health outcomes, WHO's framework for action. Geneva: WHO, 2007.

25. Mounier-Jack S, Griffiths UK, Closser S, et al. Measuring the health systems impact of disease control programmes: a critical reflection on the WHO building blocks framework. BMC Public Health 2014;14:278.

26. van Olmen J, Marchal B, Van Damme W, et al. Health systems frameworks in their political context: framing divergent agendas. BMC Public Health 2012;12:774.

27. Risso-Gill I, McKee M, Coker R, et al. Health system strengthening in Myanmar during political reforms: perspectives from international agencies. Health Policy Plan 2014;29:466-74.

28. Mutale W, Bond V, Mwanamwenge MT, et al. Systems thinking in practice: the current status of the six WHO building blocks for health system strengthening in three BHOMA intervention districts of Zambia: a baseline qualitative study. BMC Health Serv Res 2013;13:291.

29. Bowling A. Research methods in health: investigating health and health services. 3rd edn. Maidenhead: Open University Press, 2009

30. Strauss A. Qualitative analysis for social scientists. Cambridge: Cambridge University Press, 1987.

31. Charmaz K. Constructing grounded theory: a practical guide through qualitative analysis. London: Sage, 2006.

32. Tong A, Sainsbury P, Craig J. Consolidated criteria for reporting qualitative research (COREQ): a 32-item checklist for interviews and focus groups. Int J Qual Health Care 2007;19:349-57.

33. Cetorelli V, Shabila NP. Expansion of health facilities in Iraq a decade after the US-led invasion, 2003-2012. Confl Health 2014;8:16.

34. Balabanova D, McKee M, Mills A, et al. What can global health institutions do to help strengthen health systems in low income countries? Health Res Policy Syst 2010;8:22.

35. Roome E., Raven J, Martineau T. Human resource management in post-conflict health systems: review of research and knowledge gaps. Confl Health 2014;8:18.

36. MOH. Resoluations of the 2nd South Sudan Health Sector Summit. Government of South Sudan, 2013.

37. Kevany S, Hatfield A, Workneh NG, et al. Diplomatic and operational adaptations to global health programmes in post-conflict settings: contributions of monitoring and evaluation systems to health sector development and 'nation-building' in South Sudan. Med Confl Surviv 2012;28:247-62.

38. Buse K, Walt G. An unruly melange? Coordinating external resources to the health sector: a review. Soc Sci Med 1997;45:449-63.
39. Cometto G, Fritsche G, Sondorp E. Health sector recovery in early post-conflict environments: experience from southern Sudan. Disasters 2010;34:885-909.

40. Baird M. Service delivery in fragile and conflict-affected statesWorld Development Report 2011-background paper. Washington DC: World Bank, 2011.

41. OECD. Service delivery in fragile situations. Key concepts, findings and lessons. Paris: OECD, 2008.

42. Barfield T, Nojumi N. Bringing more effective governance to Afghanistan: 10 pathways to stability. Middle East Policy Archives, 2009. http://www.mepc.org/journal/middle-east-policy-archives/ bringing-more-effective-governance-afghanistan-10-pathwaysstability

43. Bornemisza O, Ranson MK, Poletti TM, et al. Promoting health equity in conflict-affected fragile states. Soc Sci Med 2010;70:80-8.

44. Kruk ME, Freedman LP, Anglin GA, et al. Rebuilding health systems to improve health and promote statebuilding in post-conflict countries: a theoretical framework and research agenda. Soc Sci Med 2010;70:89-97.

45. Eldon J., Waddington C., Hadi Y. Health system reconstruction: Can it contribute to state-building? London: HLSP, 2008.

46. Sondorp E, Ter Veen A, Howard N. Health in state-building and peace-building. In: Howard N, Sondorp E, Ter Veen A, eds. Conflict and health. Open University Press, 2012:155-60.

47. Boege V, Brown A, Clement K, et al. On hybrid political orders and emerging states: state formation in the context of 'fragility'. Berlin: Berghof Research Centre for Constructive Conflict Management, 2008.

48. Kevany S. Global health diplomacy, 'smart power', and the new world order. Global Public Health 2014;9:787-807.

49. da Costa D. Working in challenging environments: risk management and aid culture in South Sudan: field report South Sudan, in ESRC-DFID grant RES-167-25-0439: achieving policy coherence in challenging environments: risk management and aid culture in Sudan and Afghanistan. Bristol: University of Bristol, 2012.

50. Shakarishvili G, Lansang MA, Mitta V, et al. Health systems strengthening: a common classification and framework for investment analysis. Health Policy Plan 2011;26:316-26.

51. da Costa D, Karlsrud J. Contextualising liberal peacebuilding for local circumstances: unmiss and local peacebuilding in South Sudan. J Peacebuilding Dev 2012;7:53-66.

52. Howard N, Sondorp E, ter Veen A. Conflict and health. Understanding public health. Open University Press, 2012. 